\title{
Synthesis and luminescence properties of europium doped silica thin film
}

\author{
Yuen Yung Hui ${ }^{a, *}$, Ching-Fuh Lin ${ }^{\text {a,b }}$ \\ ${ }^{a}$ Graduate Institute of Electro-optical Engineering, National Taiwan University, No. 1, Sec. 4, Roosevelt Road, Taipei, Taiwan, R.O.C. \\ ${ }^{\mathrm{b}}$ Graduate Institute of Electronics Engineering, and Department of Electrical Engineering, National Taiwan University, Taiwan, R.O.C.
}

Received 20 October 2006; accepted 18 December 2006

Available online 23 December 2006

\begin{abstract}
Mixture of europium oxide $\left(\mathrm{Eu}_{2} \mathrm{O}_{3}\right)$ nanoparticles and spin-on glass (SOG) solution without annealing exhibited a strong room temperature photoluminescence (PL) at $610 \mathrm{~nm}$. We developed a one-step synthesis to incorporate europium ions in silica thin film by mixing the Eu $\mathrm{O}_{3}$ nanoparticles with the SOG solution and found that the weight ratio of the nanoparticles and the SOG solution was 1:5 for maximum PL. We also studied the temperature effect on the light emission of the europium doped thin film by time-of-flight secondary ion mass spectrometry (SIMS). The PL intensity of the thin film doubled after annealing. SIMS study confirmed the reduction of hydroxyl groups and explained the PL enhancement in the annealed europium doped silica thin film.
\end{abstract}

(C) 2006 Elsevier B.V. All rights reserved.

Keywords: Europium; Glasses; Luminescence; Photoluminescence; Secondary ion mass spectrometry; Silica

\section{Introduction}

The trivalent europium ions have been extensively applied in display and DNA technology because of the intense luminescence near $610 \mathrm{~nm}$. As the chemical environment of the europium ions influences the light emission, europium ions have been studied in different host materials, such as silica [1], yttria [2], lutetium oxide [3] and gallium nitride [4]. For instance, europium ions have been introduced into silica material by ion implantation [1], radio frequency sputtering [5], spray pyrolysis method [6] and sol-gel method [7]. In addition, thermal annealing $[1,8]$ on the europium doped silica thin film after growth could enhance the photoluminescence (PL).

Sol-gel method is widely adopted to incorporate europium ions into silica material but involves a number of chemical processes. In this report, we applied the spin-on glass (SOG) solution to fabricate europium doped silica thin film. Our fabrication method did not require organic complexation of europium ions. The europium doped sample was deposited just simply by spin-coating, as the spin-coating solution was a SOG solution which contained europium oxide $\left(\mathrm{Eu}_{2} \mathrm{O}_{3}\right)$ nanoparti-

\footnotetext{
* Corresponding author. Tel.: +88623366 3540; fax: +8862 23642603 .

E-mail addresses: yyhui@cc.ee.ntu.edu.tw (Y.Y. Hui), cflin@cc.ee.ntu.edu.tw (C.-F. Lin).
}

cles. We studied both the europium concentration and temperature effect on the PL of the film samples and investigated the chemical environment of the europium ions in the silica thin film upon annealing by secondary ion mass spectrometry (SIMS).

\section{Experimental}

Europium doped silica thin films were prepared by spincoating. A pre-determined amount of $\mathrm{Eu}_{2} \mathrm{O}_{3}$ nanoparticles was added to the commercially available SOG solution. The SOG solution, which was manufactured by Filmtronics Inc., contained silanol groups. The diameter of the $\mathrm{Eu}_{2} \mathrm{O}_{3}$ nanoparticles ranged between $43 \mathrm{~nm}$ and $58 \mathrm{~nm}$. Then the prepared solution was stirred in an ultrasonic bath for 15 min and was then spun on a Si substrate at $3000 \mathrm{rpm}$ for $40 \mathrm{~s}$. Afterward the samples were heated up in a furnace with a ramp of $5{ }^{\circ} \mathrm{C}$ per minute, according to our annealing temperature. The samples were then annealed at high temperature for $90 \mathrm{~min}$ and cooled to room temperature.

The PL of the europium doped samples was further collected at room temperature with an excitation laser at the wavelength of $266 \mathrm{~nm}$. The light emission was spectrally analyzed by a monochromator and a photomultiplier tube. The film samples exhibited strong red luminescence at $610 \mathrm{~nm}$ and the PL 


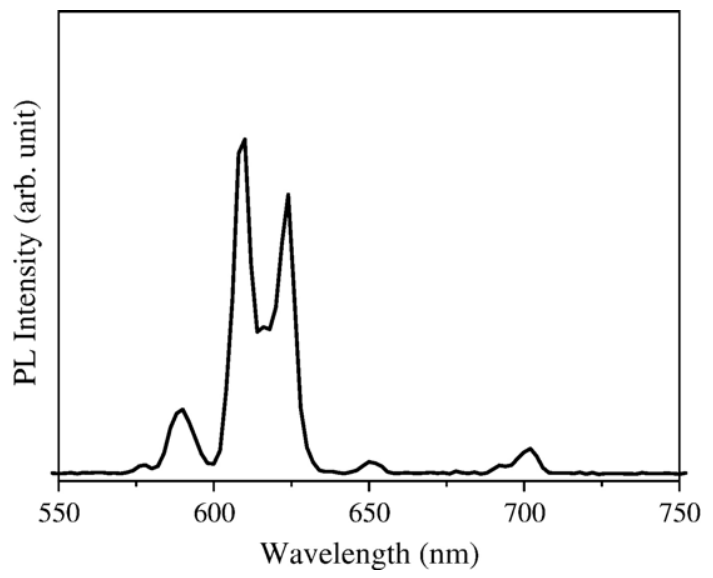

Fig. 1. PL spectrum of europium doped SOG thin film.

intensity of the film sample varied with the preparation condition. The chemical environment of the europium ions was then probed by the time-of-flight secondary ion mass spectrometry (ToF-SIMS). The primary ion source was a pulsed ${ }^{69} \mathrm{Ga}^{+}$source operated at $25 \mathrm{keV}$. A pulse repetition frequency of $10 \mathrm{kHz}$ was employed. The SIMS spectra were recorded after the samples were sputtered cleaned. Electron flooding was applied for charge compensation during our experiment. We compared the SIMS spectra of the annealed and un-annealed samples and found out the change in chemical structure of the film sample during annealing.

\section{Results and discussion}

Fig. 1 displayed the PL spectra at ambient for our europium doped thin film prepared at room temperature. Upon excitation europium doped sample exhibited strong red luminescence. The emission bands corresponded to the ${ }^{5} \mathrm{D}_{0} \rightarrow{ }^{7} \mathrm{~F}_{J}(J=1,2,3,4)$ transitions of $\mathrm{Eu}^{3+}$ ions, which were mainly contributed by the localized rare earth $4 \mathrm{f}$ energy levels. The ${ }^{5} \mathrm{D}_{0} \rightarrow{ }^{7} \mathrm{~F}_{1}$ transition at $590 \mathrm{~nm}$ was the parity-allowed magnetic dipole transition $(\Delta J=1)$, and its intensity was not influenced by the host environment. In contrast, the ${ }^{5} \mathrm{D}_{0} \rightarrow{ }^{7} \mathrm{~F}_{2}$ electric dipole transition at $610 \mathrm{~nm}(\Delta J=2)$ was very sensitive to the local environment around the europium ion and its intensity depended on

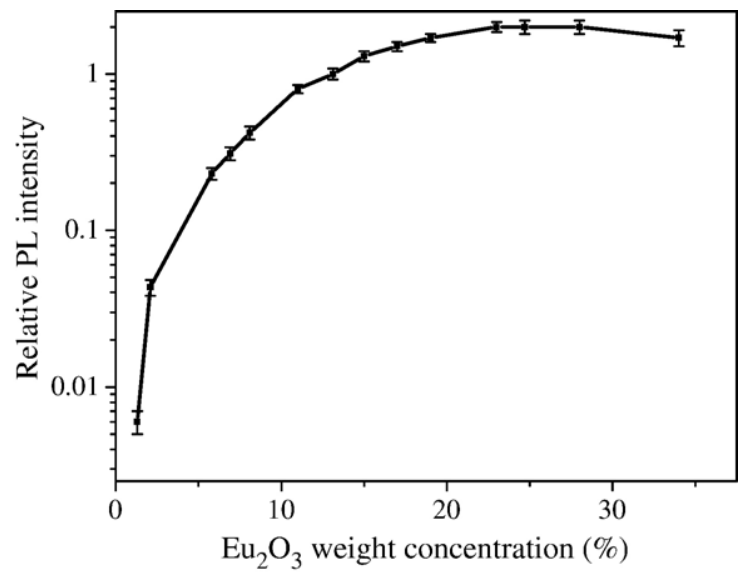

Fig. 2. Variation of the relative PL peak intensity with different weight percentages of $\mathrm{Eu}_{2} \mathrm{O}_{3}$ nanoparticles in SOG film.

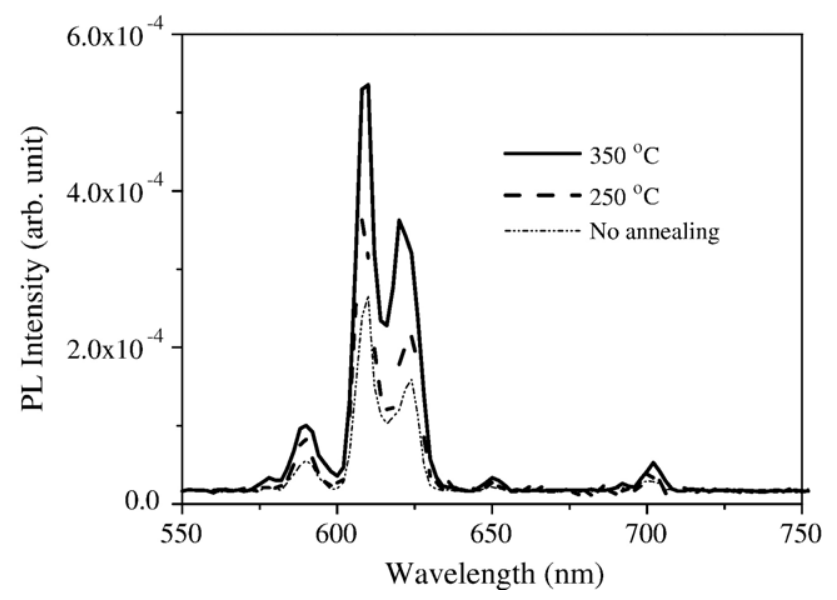

Fig. 3. PL comparison of europium doped SOG thin film prepared at different annealing temperatures.

the symmetry of the crystal field around the europium ion. A low symmetry around the europium ion increased the intensity of the electric dipole transition. Hence, the observation of the fine splitting for the transition revealed the low symmetry in our europium doped thin film. Also, we could identify the emission bands at $650 \mathrm{~nm}$ and $700 \mathrm{~nm}$, which originated from ${ }^{5} \mathrm{D}_{0} \rightarrow{ }^{7} \mathrm{~F}_{3}$ and ${ }^{5} \mathrm{D}_{0} \rightarrow{ }^{7} \mathrm{~F}_{4}$ transitions. Moreover, we did not observe any peak in the low wavelength region. In the organic sol-gel derived silica glass, a broad emission band in the blue region between 400 and $500 \mathrm{~nm}$ was found in addition to these red narrow transitions [9]. This emission band was commonly found in the europium-phen complex doped sample. Our europium doped thin film provided a pure red light emission.

As the $\mathrm{Eu}_{2} \mathrm{O}_{3}$ nanoparticles were the resources of europium ions in our fabrication of thin film, the amount dissolved in the SOG has strong influence on the PL emission [3]. We further added different amounts of $\mathrm{Eu}_{2} \mathrm{O}_{3}$ nanoparticles to the SOG solution and carried out PL experiments. The weight percentage of $\mathrm{Eu}_{2} \mathrm{O}_{3}$ nanoparticles ranged between $1 \%$ and $30 \%$. Its PL peak intensity vs. the weight percentages of $\mathrm{Eu}_{2} \mathrm{O}_{3}$ nanoparticles was shown in Fig. 2. The emission intensity significantly increased with the weight percentages of $\mathrm{Eu}_{2} \mathrm{O}_{3}$ nanoparticles up to $25 \%$. As the weight percentage was beyond $25 \%$, the light emission intensity decreased. The optimum weight percentage for $\mathrm{Eu}_{2} \mathrm{O}_{3}$ in our $\mathrm{SOG}$ system was about $25 \%$. The PL saturation was contributed by the concentration quenching. Dai et al. [10] reported concentration quenching in erbium doped silica system. When the rare earth metal ion concentration was too high, the ions tended to aggregate and cluster in the host material. During PL, the excitation laser energy transfer among ions became possible, as the spatial separation among ions decreased sufficiently. This energy transfer mechanism led to a decline in PL and concentration quenching resulted. Our europium doped sample also suffered from concentration quenching, when the concentration was beyond $25 \%$.

Table 1

Integrated secondary ion intensity for europium doped SOG thin film with and without annealing

\begin{tabular}{lll}
\hline Positive ion & Without annealing & Annealing at $350{ }^{\circ} \mathrm{C}$ \\
\hline $\mathrm{EuOH}^{+}(170)$ & 19.4 & 11.6 \\
$\mathrm{EuO}_{2} \mathrm{H}_{2}^{+}(187)$ & 10.1 & 5.87 \\
$\mathrm{Eu}_{2} \mathrm{O}_{3} \mathrm{H}^{+}(353)$ & $19.0 \times 10^{-2}$ & $9.52 \times 10^{-2}$ \\
\hline
\end{tabular}

The mass-to-charge ratio is specified in the blanket. 
We also investigated the annealing temperature (below $400{ }^{\circ} \mathrm{C}$ ) effect on the PL of europium doped samples and compared the PL spectra. The PL spectra of the film samples without annealing and annealed at $250{ }^{\circ} \mathrm{C}$ and $350{ }^{\circ} \mathrm{C}$ were illustrated in Fig. 3. All samples displayed a sharp peak at $610 \mathrm{~nm}$, which was characteristic for the ${ }^{5} \mathrm{D}_{0} \rightarrow{ }^{7} \mathrm{~F}_{2}$ transition of europium ion. Fig. 3 also demonstrated that the PL intensity increased with the annealing temperature, which was reported in other europium doped silica systems [5]. The PL peak intensity of the europium doped sample after furnace annealing at $350{ }^{\circ} \mathrm{C}$ was 2 times higher than that without annealing. As the annealing temperature further increased, the PL intensity saturated.

Finally the chemical environment of the europium ion in the film samples was probed by ToF-SIMS. We selected the samples without annealing and annealed at $350{ }^{\circ} \mathrm{C}$ for our SIMS analysis. The major ion fragments in the low-mass side (below 70) were due to $\mathrm{Si}-$, and $\mathrm{SiO}-$ related structure respectively. On the high-mass side (above 150), the major ion fragment was due to europium-related ion. For instance, peaks corresponding to the europium ion $(m / z=151,153)$ were detected. The ion intensities of europium ion agreed with the natural isotopic abundance ratio. We also found $\mathrm{EuSiO}^{+}(\mathrm{m} / \mathrm{z}=195,196,197$, 198 and 199) and $\mathrm{EuSiO}_{2}^{+}(m / z=211,212,213,214$ and 215) ions, which was a hint to the presence of the $\mathrm{Eu}-\mathrm{O}-\mathrm{Si}$ direct linkage.

$\mathrm{OH}$ groups were the well-known quenching sites for PL. Table 1 displayed the secondary ion from the europium doped samples, without annealing and annealing at $350{ }^{\circ} \mathrm{C}$. We selected the isotope of $\mathrm{EuOH}^{+}$ $(m / z=170), \mathrm{EuO}_{2} \mathrm{H}_{2}^{+}(m / z=187)$ and $\mathrm{Eu}_{2} \mathrm{O}_{3} \mathrm{H}^{+}(m / z=352)$ for our comparison. $\mathrm{Eu}(\mathrm{OH})_{n}^{+}$was derived from $\mathrm{OH}$ groups in the film sample. The intensities for the europium ions coupled with $\mathrm{OH}$ groups, $\mathrm{EuOH}^{+}$ and $\mathrm{EuO}_{2} \mathrm{H}_{2}^{+}$, dropped by $40 \%$. We also found that the intensity for other isotopes of europium ions coupled with $\mathrm{OH}$ groups behaved similarly as the annealing temperature rose. It implied that the $\mathrm{OH}$ content decreased after the film sample was annealed. It was proposed that annealing eliminated $\mathrm{OH}$ quenching sites in the europium doped silica thin film [8]. Our SIMS result confirmed the explanation.

\section{Conclusion}

In conclusion, we developed a one-step method to incorporate rare earth metal ions into the silica film by the
SOG solution. Without annealing, a strong and stable ${ }^{5} \mathrm{D}_{0} \rightarrow{ }^{7} \mathrm{~F}_{2}$ transition of europium ion in silica was observed. We studied the PL and the SIMS of the europium doped thin films upon annealing. The PL intensity of the film samples was enhanced by furnace annealing at $350{ }^{\circ} \mathrm{C}$. The SIMS result demonstrated that annealing diminished the $\mathrm{OH}$ content in the europium doped thin film. We hence explained the PL enhancement of the film sample upon annealing by the reduction of the $\mathrm{OH}$ groups.

\section{Acknowledgements}

This work is supported by the National Science Council, Taiwan, Republic of China, with Grant Nos: NSC94-2120-M002-010, NSC94-2112-M-002-009 and NSC94-2622-E-002005. We are also grateful for the SIMS experiment in the Department of Chemistry, National Tsing Hua University, Taiwan.

\section{References}

[1] N. Can, P.D. Townsend, D.E. Hole, H.V. Snelling, J.M. Ballesteros, C.N. Afonso, J. Appl. Phys. 78 (1995) 6737.

[2] S. Ray, P. Pramanik, A. Singha, A. Roy, J. Appl. Phys. 97 (2005) 094312.

[3] E. Zych, A. Meijerink, C. de Mello Donegá, J. Phys., Condens. Matter 15 (2003) 5145

[4] H. Wu, C.B. Poitras, M. Lipson, M.G. Spencer, J. Hunting, F.J. DiSalvo, Appl. Phys. Lett. 88 (2006) 011921.

[5] J. Qi, T. Matsumoto, M. Tanaka, Y. Masumoto, J. Phys., D Appl. Phys. 33 (2000) 2074.

[6] V. Jokanović, M.D. Dramićanin, Ž. Andrić, Acta Chim. Slov. 53 (2006) 23.

[7] H.J. Zhang, L.S. Fu, S.B. Wang, Q.G. Meng, K.Y. Yang, J.Z. Ni, Mater. Lett. 38 (1999) 260.

[8] D. Hreniak, M. Jasiorski, K. Maruszewski, L. Kepinski, L. Krajczyk, J. Misiewicz, W. Strek, J. Non-Cryst. Solids 298 (2002) 146.

[9] M.H. Bartl, B.J. Scott, H.C. Huang, G. Wirnsberger, A. Popitsch, B.F. Chmelka, G.D. Stucky, Chem. Commun. 21 (2002) 2474.

[10] S. Dai, C. Yu, G. Zhou, J. Zhang, G. Wang, L. Hu, J. Lumin. 117 (2006) 39. 